\title{
WORKFORCE Gender balance in an unprecedented time
}

\author{
Authors: Rose Penfold ${ }^{A}$ and Lucia Magee ${ }^{B}$
}

\begin{abstract}
As the NHS responds to the ongoing COVID-19 pandemic, the strain is being felt across the entire workforce. Both direct effects of COVID-19 and the response to the crisis are unearthing a number of societal inequalities, not least, those relating to gender. The fact that women play a disproportionate role in frontline health and social care roles and perform the majority of caregiving responsibilities is more exposed than ever before. Concurrently, the underrepresentation of women in senior clinical and leadership roles is being brought into stark relief. Redressing gender imbalance across health and social care is vital if we are to translate experience and learnings from our frontline workforce into our national preparedness and response effort. It is also important as we continue to promote wider gender and health equity goals within society. While we focus on responding to the current situation, an opportunity arises for greater value to be assigned to frontline health and caregiver roles. We must raise the profile of women leaders who are taking a stand during this crisis and use this opportunity to ensure that our future health and social care leadership reflects the wider workforce and the population.
\end{abstract}

KEYWORDS: Gender balance, leadership, COVID-19

DOI: $10.7861 /$ fhj.2020-0029

\section{Background}

The disease pandemic caused by the SARS-CoV-2 virus (and the COVID-19 disease) continues to sweep the globe and leave a turbulent and destructive trail in its wake. As the NHS responds to, arguably, the greatest challenge it has faced in over 70 years of history, the huge strain is being felt across the entire workforce. During this time, both the direct effects of COVID-19 and the response to the crisis are unearthing a number of societal inequalities, not least, those relating to gender. The fact that women play a disproportionate role in frontline health and social care roles and perform the majority of caregiving responsibilities is more clearly exposed than ever before. At the same time, the significant underrepresentation of women in senior clinical and leadership roles is being brought into stark relief. Redressing gender imbalance across the health and social care sector is vital if we are to translate the experience from the

Authors: A academic clinical fellow in geriatric medicine, Guy's and St Thomas' NHS Foundation Trust, London, UK; ' ${ }^{\text {academic clinical }}$ fellow in primary care, NHS Improvement, London, UK frontline workforce into national preparedness and the response effort. It is also important to continue to promote wider gender and health equity goals within society. While the population focuses on responding to the current situation, at the same time, an immense opportunity arises for greater value to be assigned to frontline health and caregiver roles. The profile of women leaders who are taking a stand during this crisis is essential to ensure that future health and social care leadership reflects both the wider workforce and the population that it serves, with true gender balance.

\section{The role of gender in times of crisis}

The SARS-CoV-2 virus does not systematically discriminate on the basis of biological sex. Sex-disaggregated data published from China suggest that roughly equal numbers of men and women have been infected with the virus, however, since these data are incomplete, findings should be interpreted with caution. ${ }^{1}$ In this same data set, there appears to be a sex-based difference in mortality and vulnerability to the disease, with men worse affected and more likely to die than women. Given all this, why the focus on women? This is because a key issue is how exposure and vulnerability to disease may be determined by assigned gender roles within society, not purely by biological sex.

Globally, women comprise over $70 \%$ of the health and social care workforce. ${ }^{2}$ Women are more commonly the primary caregiver within the household and perform the majority of caregiving roles within society. Experience from past disease outbreaks suggests that incorporation of gender analysis into epidemic preparedness and response efforts is vital. ${ }^{3}$ Not only does it facilitate tailoring of the response to improve the effectiveness of health interventions, but it can also promote wider gender and health equity goals. For example, during the Ebola outbreak in west Africa in 2014-16, women were more likely to be infected with the virus than men. ${ }^{4}$ This is not because the $Y$ chromosome somehow confers a degree of protection against infection, but instead reflects the predominant role played by women as caregivers and frontline healthcare workers during the epidemic. It is now several years on, and the majority of caregivers and frontline healthcare workers are still women, not only in west Africa but also in the majority of countries around the world, including the UK. Recent analysis from The King's Fund illustrates that $77 \%$ of staff directly employed in England's NHS are women, with a significant gender-related pay gap when compared to their male counterparts in the sector. ${ }^{5}$ One of the positive things to arise from such a time of crisis is increased appreciation for the important and challenging role played by our frontline workforce. This has been exemplified for example through direct messages of support on mainstream and social media, charitable donations and the 'Clap for carers' (a 
national demonstration of gratitude and support) having taken place on Thursday evenings in the UK. We need to ensure that our caregivers and healthcare workers continue to receive recognition beyond the duration of the crisis for performing the vital roles that form the backbone of our society.

Furthermore, issues surrounding procurement, distribution and provision of adequate personal protective equipment (PPE) have been the focus of significant national attention and discourse throughout the COVID-19 pandemic. A number of reports suggest that health and social care providers in the community (the majority of whom are women) are not always able to access adequate protection when compared to colleagues working in the acute healthcare sector, as recently highlighted by a commentary in the $B M J]^{6}$ The issue of adequate protection may have a greater impact on women than men; in her international bestselling book Invisible Women, Caroline Criado Perez highlights that $71 \%$ of women across a range of industries wear protective work clothing that is not designed for women's body size and shapes. From personal experience, we would suggest that a significant amount of the PPE women are currently provided to wear in healthcare settings may have been designed to fit men; also face masks that have to be self 'fit-checked', with insufficient capacity to properly fit-test face masks in a large number of healthcare settings. As a society, we owe women sufficient and appropriate PPE to adequately protect both their own health and that of those around them as they continue to serve health and social care services on the front line.

\section{Amplifying the voices of women leaders}

Women remain significantly underrepresented in leadership. It is perhaps striking that not one of the key members of the leadership team at the now closed Nightingale Hospital in London, including the chief executive and deputy chief executive, were women. While most of the daily briefings have been delivered by three male members of the political, medical and scientific leadership, Dr Jenny Harries, deputy chief medical officer, Prof Yvonne Doyle, medical director and director of health protection for Public Health England, and Ruth May, chief nursing officer, have all taken to the stand to present the latest figures and field questions. We also note the leadership of Dr Nikki Kanani throughout this time as medical director for primary care at NHS England and NHS Improvement. There are a number of international examples of strong women leaders at this time, including New Zealand's Prime Minister Jacinda Ardern and German Chancellor Angela Merkel, among others. Female leaders taking a visible and prominent stand, especially at times of national crisis, is a key component of role modelling for aspiring future leaders: we cannot be what we cannot see.

Diversity of leadership styles is very important for effective teamwork and that greater diversity, including gender, leads to better outcomes for organisations, including in healthcare. ${ }^{7}$ Mainstream media attention often focuses on those leading the national response and on the lead authors of key publications informing these decisions. It is important to recognise the vast contribution of thousands of women working in clinical roles and also as laboratory scientists, epidemiologists and in other research roles. It is impossible to list them all here, but we note for example the women working at the Medical Research Council Centre for Global Infectious Disease at Imperial College London and those in a team at King's College London analysing data from the international COVID-19 Symptom Study app. We note the contribution of women leaders in health education, with the recent appointment of Dr Navina Evans as chief executive officer (CEO) at Health Education England, supported by acting CEO Prof Wendy Reid and acting executive medical director Prof Sheona MacLeod. Women Speakers in Healthcare (WSH) was co-founded by five NHS healthcare professionals, with the ambitious aim to achieve gender balance at all healthcare conferences and events, with parity of opportunity for all. ${ }^{8}$ The organisation has collated the largest database of women speakers across health and social care in the UK and strives to promote balanced representation at all healthcare conferences and events. Gender parity will not be achieved without male support and engagement of both male and female colleagues across the health and social care sector. Even at this challenging time, many are continuing to make a stand for greater gender balance across health and social care.

\section{Conclusion}

We must ensure that we learn from the vast experiences of our caregivers and frontline health and social care workers, the majority of whom are women. We must also fulfil our responsibility to recognise their immense contributions to society and to adequately protect them as they continue to serve others. Diversity of leadership is vital both to achieve better healthcare outcomes and as positive role modelling for future aspiring leaders. We must highlight gender imbalance where it occurs and continue to strive for local and national leadership teams that are gender balanced and representative of both the wider health and social care workforce, and the general population. Responding to the ongoing COVID-19 pandemic is undoubtedly one of the greatest challenges the human race has ever faced. It is in the face of such adversity that gender balance and greater diversity of leadership can flourish and amplify.

\section{References}

1 The Novel Coronavirus Pneumonia Emergency Response Epidemiology Team. The epidemiological characteristics of an outbreak of 2019 novel coronavirus disease (COVD-19). China CDC Weekly 2020;2:113-22.

2 World Health Organization. Gender Equity in the health workforce: Health workforce working paper 1. WHO, 2019. https://apps.who. int/iris/bitstream/handle/10665/311314/WHO-HIS-HWF-GenderWP1-2019.1-eng.pdf?sequence $=1$ \&isAllowed $=y$ [Accessed 10 April 2020].

3 Wenham C, Smith J, Morgan R. COVID-19: the gendered impacts of the outbreak. Lancet 2020;395:846-8.

4 Davies S, Bennett B. A gendered human rights analysis of Ebola and Zika: locating gender in global health emergencies. International Affairs 2016;92:1041-60.

5 The King's Fund. The health care workforce in England: make or break? The King's Fund, 2018. www.kingsfund.org.uk/publications/ health-care-workforce-england [Accessed 10 April 2020].

6 Rimmer A. Covid-19: GPs call for same personal protective equipment as hospital doctors. BMJ 2020;368:m1055.

7 Beilock S. How diverse teams produce better outcomes. Forbes, 2019. www.forbes.com/sites/sianbeilock/2019/04/04/how-diversity-leadsto-better-outcomes/\#2e8962dd65ce [Accessed 10 April 2020].

8 Penfold R, Knight K, Al-Hadithy N, Magee L, McLachlan G. Women speakers in healthcare: speaking up for balanced gender representation. FHJ 2019;6:167-71.

Address for correspondence: Dr Rose Penfold, Guy's and St Thomas' NHS Foundation Trust, Westminster Bridge Road, London SE1 7EH, UK.

Email: rose.penfold1@nhs.net 